J ournal of Bangladesh Chemical Society, Vol. 25(1), 53-61, 2012

\title{
REMOVAL OF CHROMIUM FROM TANNERY EFFLUENT USING CHITOSAN-CHARCOAL COM POSITE
}

SHAJAHAN SIRAJ ${ }^{1}$, MD. MONARUL ISLAM ${ }^{1, *}$, PROKASH CHANDRA DAS ${ }^{2}$, SHAH MD. MASUM $^{3}$, ISMET ARA JAHAN ${ }^{1}$, MD. AMINUL AHSAN ${ }^{1}$ AND MD. SHAJAHAN ${ }^{2}$

${ }^{1}$ Bangladesh Council of Scientific and Industrial Research (BCSIR), Dhanmondi, Dhaka-1205, B angladesh.

2D epartment of Chemistry, J agannath U niversity, D haka-1100, B angladesh.

${ }^{3}$ Department of Applied Chemistry \& Chemical Engineering, U niversity of Dhaka, Dhaka-1000, Bangladesh

\section{Abstract}

Chitosan-charcoal composite was applied as a media to treat tannery effluent. The composite was prepared by a simple solution-evaporation method and the morphology of the prepared composite was characterized by scanning electron microscopy (SEM) and $\mathrm{X}$-ray diffraction $(\mathrm{XRD})$. Adsorption of chromium $(\mathrm{Cr})$ was investigated by varying the contact time between adsorbate $(\mathrm{Cr})$ and composite, $\mathrm{pH}$ of solution and dose of composite. The concentration of $\mathrm{Cr}$ was determined by atomic absorption spectroscopy (AAS). Removal of $\mathrm{Cr}$ was found to be dependent on $\mathrm{pH}$ and maximum adsorption was observed at $\mathrm{pH}$ 4.0. The optimum dose and contact time for $\mathrm{Cr}$ treatment was $40 \mathrm{~g} / \mathrm{L}$ and 250 minutes respectively. The results showed that prepared composite can be used efficiently for the treatment of tannery wastewater containing chromium.

\section{Introduction}

At least 20 metals are classified as toxic and half of these are present in the environment in sufficient quantities that pose risks to human health ${ }^{1}$. Chromium and its compounds are toxic, which are being mixed with natural water from a variety of industrial effluents. The major sources are from textile dyeing, leather tanning, electroplating and metal finishing industries, as well as from oxidative dyeing and water cooling towers which cause severe environmental and public health problems ${ }^{2}$. It leads to liver damage, pulmonary congestion, oedma and causes skin irritation as well as results in ulcer formation ${ }^{3}$. The concentration of $\mathrm{Cr}$ in industrial wastewater was found in the range of $0.5 \mathrm{mg} / \mathrm{L}$ to $270000 \mathrm{mg} / \mathrm{L}^{4}$. The tolerance limit for the discharge of $\mathrm{Cr}(\mathrm{VI})$ into inland surface water is $0.1 \mathrm{mg} / \mathrm{L}$ and in potable water it is $0.05 \mathrm{mg} / \mathrm{L}^{5}$. Chromium exists in the environment in two oxidation states i.e. $\mathrm{Cr}(\mathrm{VI})$ and $\mathrm{Cr}(\mathrm{III})$. $\mathrm{Cr}(\mathrm{III})$ is a nutrient species used for control of glucose and lipid metabolism in membranes, while $\mathrm{Cr}(\mathrm{VI})$ is highly carcinogenic and mutagenic due to its high oxidative character ${ }^{6,7,8}$. Owing to these contradicting characteristics, chromium contamination is a hot topic in modern analytical chemistry . Chitosan (2-amino-2-deoxy- $\beta$ - D-glucopyranose) (Fig.1.(b).) is a deacetylated derivative of chitin (2-acetamino-2-deoxy- $\beta$-Dglucopyranose) ${ }^{10}$ (Fig.1.(a).). Due to its polycationic nature, chitosan is used as flocculating agent and acts as chelating agent and heavy metal trapper ${ }^{11}$.

\footnotetext{
*Author for Corresponding; e-mail : mmipavel@ yahoo.com
} 
Chitosan chelates five to six times the amounts of metals than chitin. This is attributed to the free amino groups exposed in chitosan because of deacetylation of chitin ${ }^{12}$. Natural biopolymers are industrially attractive because of their capability of lowering transition metal-ion concentration to parts per billion. Natural products that are available in large quantities or certain waste from agricultural operations may have potential to be used as low cost adsorbents, as they represent unused resources, widely available and are environmentally friendly ${ }^{13}$. The bio-adsorbent material chitosan is slightly soluble at low $\mathrm{pH}$ and poses problems for developing commercial applications. It is also soft and has a tendency to agglomerate or form a gel in aqueous solutions.

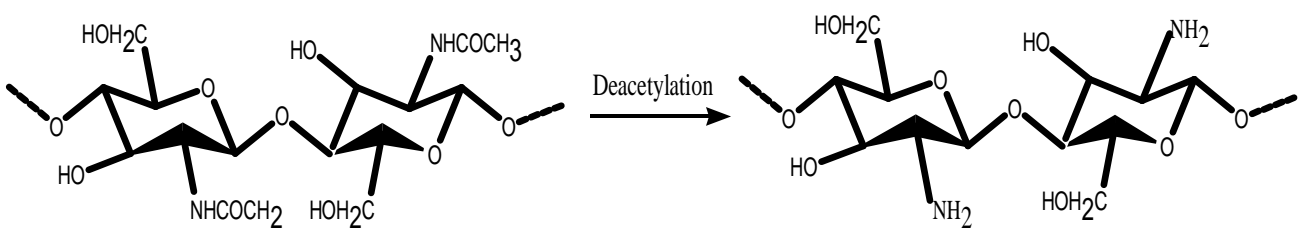

Fig. 1(a). Chitin

Fig. 1(b). Chitosan

In addition, the active binding sites of chitosan are not readily available for adsorption. Transport of the metal contaminants to the binding sites plays a very important role in process design. Therefore, it is necessary to provide physical support and increase the accessibility of the metal binding sites for process applications. The aim of this study was to develop a biocomposite of chitosan coated on charcoal for the removal of $\mathrm{Cr}$ from industrial effluents.

\section{Experimental}

\section{$M$ aterials and $M$ ethods}

\section{Raw Materials}

Shrimp shell was collected from Khulna, Bangladesh. The shell was scraped free of loose tissue, washed with cold water and dried in the sun for 2 days. Then the shell was grounded to powder. Dried ground shell was placed in opaque plastic bottles and stored at an ambient temperature for use. Activated charcoal was purchased from Merck, India and tannery wastewater was collected from Hazaribag tannery industrial area, Dhaka, Bangladesh.

\section{Preparation of chitosan and chitosan gel}

Chitosan ( $\mathrm{DD}=72 \%)$ was obtained from shrimp shell and characterized as reported earlier $^{10}$. About $50 \mathrm{~g}$ of chitosan was slowly added to $1000 \mathrm{~mL}$ of $10 \mathrm{wt} \%$ oxalic acid with constant stirring. The mixture was heated to $40-50^{\circ} \mathrm{C}$ to facilitate mixing. At room temperature, the chitosan-oxalic acid mixture formed a whitish viscous gel ${ }^{14}$. 


\section{Preparation of chitosan-charcoal composite}

About $250 \mathrm{~g}$ of the charcoal was slowly added to the chitosan gel and stirred continuously. The mixture was then dried slowly at $55-60^{\circ} \mathrm{C}$ to get the product. The gel coated charcoal was then washed with deionized water and dried. The chitosan-charcoal composite was then characterized by X-ray diffraction (XRD) and Scanning Electron Microscope (SEM).

$X$-ray diffraction (XRD)

XRD patterns of composite were recorded on Philips PWO4 Xpert pro X-ray diffractometer. The X-ray source was $\mathrm{Cu} \mathrm{K} \alpha$ with a voltage of $40 \mathrm{kV}$ and a current of 30 $\mathrm{mA}$. The measurement was in the scanning range of 5-70 at a scanning speed of $50 \mathrm{~s}^{-1}$.

Scanning Electron Microscope (SEM)

A HITACHI S-3400N, Japan (BSE) scanning electron microscope (VP-SEM) was used to examine the microstructure of chitosan and composite without any coating to the sample surface and the image was taken at an accelerated voltage of $15.0 \mathrm{kV}$.

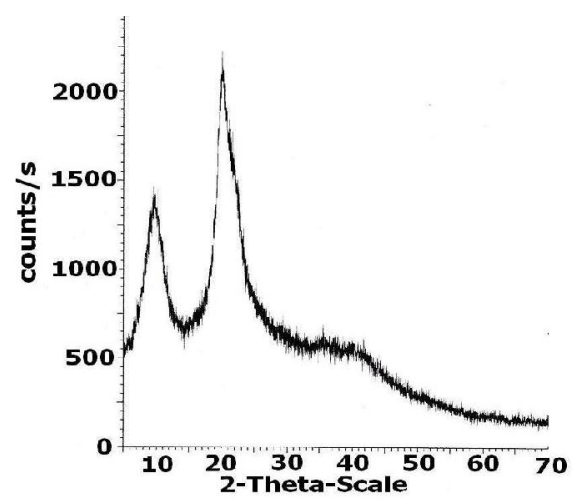

Fig. 2(a). XRD of Chitosan

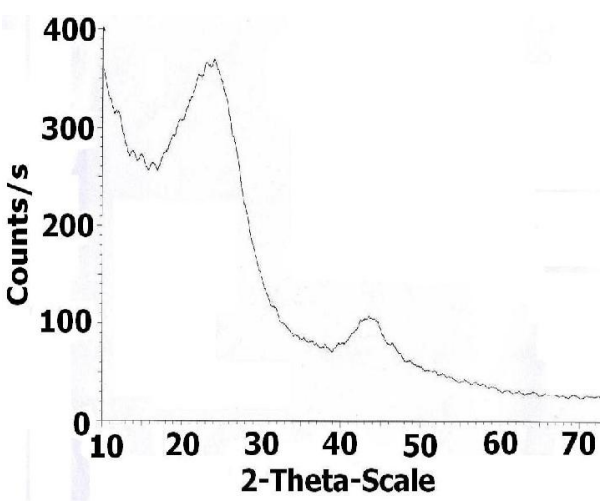

Fig. 2(b). XRD of Composite

Preparation of chromium $(\mathrm{Cr})$ stock solution

Potassium dichromate $\left(\mathrm{K}_{2} \mathrm{Cr}_{2} \mathrm{O}_{7}\right)$ (Merck, Germany) was used as the source of $\mathrm{Cr}(\mathrm{VI})$ in the solution. $0.707 \mathrm{~g}$ of $\mathrm{K}_{2} \mathrm{Cr}_{2} \mathrm{O}_{7}$ was dissolved in de-ionized water and was diluted to $500 \mathrm{~mL}$ in a volumetric flask to prepare $500 \mathrm{ppm} \mathrm{Cr}$ stock solution. Then the solution was further diluted for treatment.

Preparation of standard chromium ( $\mathrm{Cr}$ ) solution

$0.2,0.5,1.0,2.0,3.0$, and $4.0 \mathrm{ppm}$ standard solutions of $\mathrm{Cr}$ were prepared for calibration by appropriate dilution of a $1000 \mathrm{ppm}$ of chromium (stand scharlau, spain) solution. Quality control standards, duplicate samples and blanks were analyzed with samples from 
effluents to ensure the quality of analysis. Air acetylene flame was used during analysis of $\mathrm{Cr}$ by FAAS. For estimation of $\mathrm{Cr}$ atomic absorption spectrophotometer (AA-240FS Varian, Australia) was used.

\section{Comparison of $\mathrm{Cr}$ removal capacity of charcoal, chitosan and prepared composite}

To compare the $\mathrm{Cr}$ removal capacity of charcoal, chitosan and the composite, known amount $(20 \mathrm{~g} / \mathrm{L})$ of chitosan, activate charcoal and composite were added to $10 \mathrm{ppm}$ of $\mathrm{Cr}$ solution in three different polyethylene tubes. The metal solution was initially adjusted at $\mathrm{pH} 4.00$ by adding $0.1 \mathrm{M} \mathrm{HCl}$ or $0.1 \mathrm{M} \mathrm{NaOH}$. The tubes were shaken well and centrifuged (Digisystem Laboratory Inc.). The contact time of standard chromium solution and adsorbent was 4 hours.

Treatment of tannery waste water by prepared composite

Two samples were collected from Hazaribagh tannery industrial area and were analyzed in the laboratory. The physico-chemical characteristics of the samples are shown in Table1. The samples were treated with the composite materials prepared in this research at optimized condition ( $\mathrm{pH}$, contact time $\&$ dose) determined by previous experiments.

Table 1. Physico-chemical characteristics of tannery effluent

\begin{tabular}{|c|c|c|c|c|c|c|c|c|c|c|c|}
\hline $\mathrm{pH}$ & $\begin{array}{c}\text { Conductivity } \\
(\mathrm{mS} / \mathrm{cm})\end{array}$ & $\mathrm{DO}$ & $\mathrm{TSS}$ & $\mathrm{TDS}$ & $\mathrm{Cr}$ & $\mathrm{Pb}$ & $\mathrm{Mn}$ & $\mathrm{Zn}$ & $\mathrm{Cd}$ & $\mathrm{Ni}$ \\
\cline { 3 - 10 } & & \multicolumn{8}{|c|}{ Unit: $\mathrm{mg} / \mathrm{L}$} \\
\hline 4.67 & 3.94 & 5.28 & 252 & 3158 & 9.98 & 7.00 & 0.14 & 0.43 & $\mathrm{BDL}$ & $\begin{array}{c}\text { BD } \\
\mathrm{L}\end{array}$ \\
\hline 7.97 & 7.64 & 0.18 & 1168 & 5080 & 39.8 & 7.50 & 0.43 & 0.30 & $\mathrm{BDL}$ & $\begin{array}{c}\mathrm{BD} \\
\mathrm{L}\end{array}$ \\
\hline
\end{tabular}

Removal efficiency ( $E$ ) of adsorbent on chromium

The influences of several operational parameters such as dose of adsorbent, initial $\mathrm{pH}$ of $\mathrm{Cr}$ solution and contact time were investigated. The result we expressed as the removal efficiency (E) of the adsorbent on $\mathrm{Cr}$, which is defined as

$$
\mathrm{E}(\%)=\left[\left(\mathrm{C}_{\mathrm{o}}-\mathrm{C}_{1}\right) / \mathrm{C}_{\mathrm{o}}\right] \times 100
$$

Where $C_{o}$ and $C_{1}$ are the initial and equilibrium concentration of $\mathrm{Cr}$ solution $(\mathrm{mg} / \mathrm{L})$, respectively. The $\mathrm{Cr}$ concentration was determined by atomic absorption spectrophotometer according to Standard Methods ${ }^{15}$.

\section{Results and Discussion}

This research focused on to develop a suitable adsorbent for treatment of chromium contaminated industrial wastewater. To prepare the chitosan-charcoal composite, the used 
chitosan was obtained from the shrimp shell by using standard method ${ }^{10}$. A composite bio-adsorbent was prepared by coating chitosan onto charcoal as reported in the literature ${ }^{14}$.

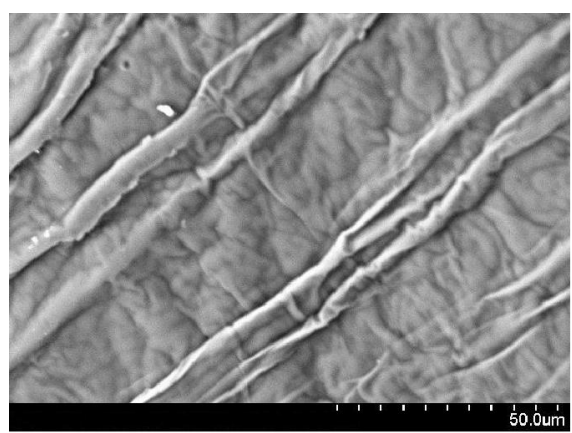

Fig. 3 (a).SEM image of Chitosan

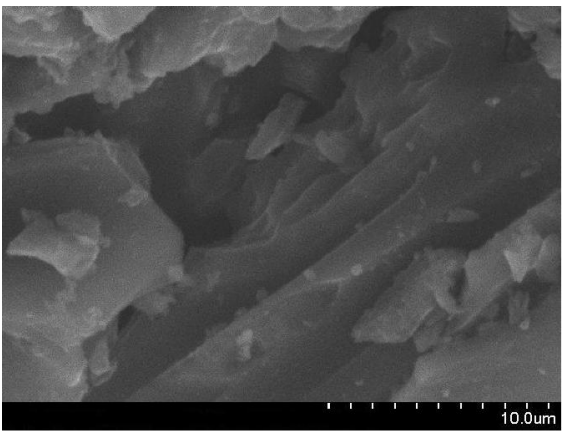

Fig. 3 (b).SEM image of composite

\section{Characterization of chitosan-charcoal composite}

The structure of chitosan-charcoal composite was characterized by scanning electron microscope (SEM) and X-ray diffraction (XRD) methods. Fig.2. showed the XRD patterns of chitosan and composite respectively. The XRD pattern in Fig.2(a). showed diffraction peak at $2 \theta=10^{\circ}$ and $21^{\circ}$ which is a typical fingerprints of semi-crystalline chitosan $^{10}$. The diffraction peak at $2 \theta=21^{\circ}$ of chitosan was shifted to about $2 \theta=25^{\circ}$ of chitosan-charcoal composite (Fig.2.(b)) which is an indication of the interaction between chitosan and charcoal. The morphology of chitosan-charcoal composite biopolymer was studied by Scanning Electron microscope (SEM). It is observed (Fig.3.) that chitosancharcoal composite biopolymers has non homogenous, non smooth surface with some porous straps and shrinkage and fibril structures whereas chitosan shows non homogenous and non smooth surface with strips and shrinkage ${ }^{10}$.

Cr removal capacity of charcoal, chitosan and prepared composite

Fig.4. represents the removal efficiency of chromium by three adsorbents charcoal, chitosan and chitosan-charcoal composite at $\mathrm{pH} 4.0$ with 4 hours contact time. The efficiency of chitosan-charcoal composite was found $98 \%$ which is higher than that of chitosan $(56.4 \%)$ and charcoal $(69.2 \%)$ due to the fact that chitosan-charcoal composite had non homogenous, non-smooth surface with some porous straps and shrinkage structure which might facilitate such removal efficiency. 


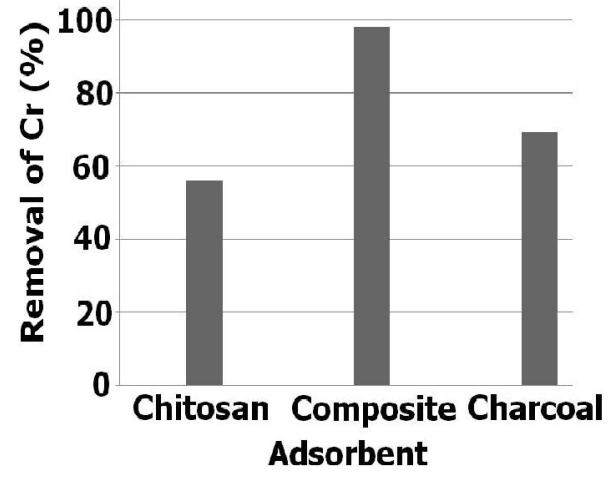

Fig. 4. Comparison of $\mathrm{Cr}$ removal efficiency

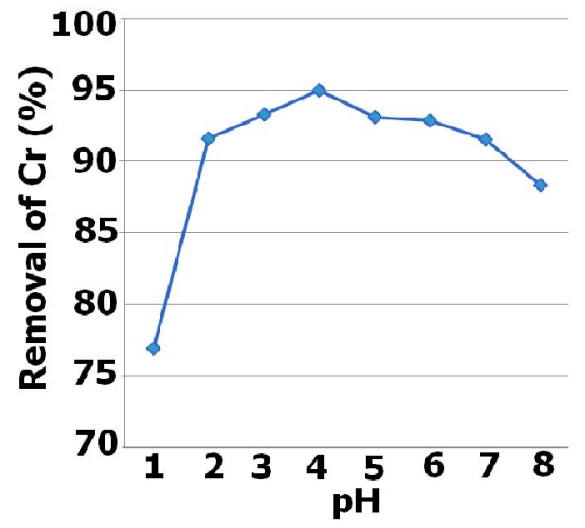

Fig. 5. Effect of $\mathrm{pH}$ on the adsorption of $\mathrm{Cr}$ on composite

$\mathrm{F}$ actors influencing the adsorption of $\mathrm{Cr}$ by composite

\section{Effect of $\mathrm{pH}$}

$\mathrm{pH}$ is an important parameter for adsorption of metal ions from aqueous solution because it affects the solubility of the metal ions, concentration of the counter ions on the functional groups of the adsorbent and the degree of ionization of the adsorbate. To examine the effect of $\mathrm{pH}$ on the $\mathrm{Cr}$ removal efficiency, the $\mathrm{pH}$ of $\mathrm{Cr}$ solution was varied from 1.0 to 8.0. As shown in Fig.5. the uptake of free ionic $\mathrm{Cr}$ depended on $\mathrm{pH}$, the optimum metal removal efficiency occurred at $\mathrm{pH} 4.0$ and then declined at higher $\mathrm{pH}$. Removal efficiency increased from $77 \%$ to $95 \%$ upon $\mathrm{pH}$ increasing from 1.0 to 4.0. At low $\mathrm{pH}$ (below 4), the amine group on chitosan was protonated to varying degree. The $\mathrm{NH}_{3}{ }^{+}$group on the chitosan was responsible for $\mathrm{Cr}$ (VI) adsorption. Chromium formed stable anions, such as $\mathrm{Cr}_{2} \mathrm{O}_{7}{ }^{2-}, \mathrm{HCrO}_{4}{ }^{-}, \mathrm{CrO}_{4}{ }^{2-}$, and $\mathrm{HCr}_{2} \mathrm{O}_{7}^{-}$, the fraction of any particular species was dependent upon the chromium concentration and $\mathrm{pH}^{16}$. During Preparation of Chitosan coated activated charcoal adsorbent, oxalic acid treatment helped to increase the availability of active binding sites on the chitosan for adsorption of $\mathrm{Cr}$ at low $\mathrm{pH}$. It was also suggested that during acid treatment, formation of more acidic surface oxides on the carbon surface enhanced its hydrophilic character and hence improved the hydrodynamic flow ${ }^{17}$. The combined active binding sites of chitosan coated charcoal showed higher adsorption capacity than chitosan and charcoal separately which is shown in Fig. 4. Hence, the optimum $\mathrm{pH}$ was around 4.0 and removal efficiency reduced drastically from $\mathrm{pH} 4$ to 8 . At higher $\mathrm{pH}$, the presence of oxygen containing functional groups made the adsorbent surface negatively charged and hence there was repulsive electrostatic interaction between the adsorbent and the anions ${ }^{18,19}$. At $\mathrm{pH}$ greater than 8.5 , insoluble chromium hydroxide started to precipitate from the solution. 


\section{Effect of dose}

The dependence of $\mathrm{Cr}$ adsorption on dose was studied by varying the amount of adsorbents from 5 to $45 \mathrm{~g} / \mathrm{L}$, by keeping the other parameters ( $\mathrm{pH}$, contact time) constant. Form the Fig.6. it could be observed that removal efficiency of the adsorbent generally increased with increasing dose. This was expected due to the fact that the higher dose of adsorbents in the solution, the greater availability of exchangeable sites for the ions. The composite showed no further increase in adsorption after a certain amount of adsorbent was added $(40-50 \mathrm{~g} / \mathrm{L})$. At $16.6 \mathrm{mg} / \mathrm{L}$ concentration of $\mathrm{Cr}$, the maximum $\mathrm{Cr}$ removal efficiency was about $95 \%$ at the dosage of $40 \mathrm{~g} / \mathrm{L}$. The observation suggested that after a certain dose of adsorbent, the maximum adsorption sets in and hence the amount of ions bound to the adsorbent and the amount of free ions remains constant even with further addition of the dose of adsorbent. Chromium and some other metals such as arsenic, depending on the $\mathrm{pH}$, are known to exist as anions. At low $\mathrm{pH}$ (below 5), the amine group

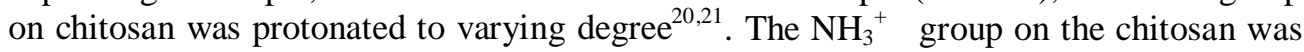
chiefly responsible for interaction with anions and negatively charged surfaces.

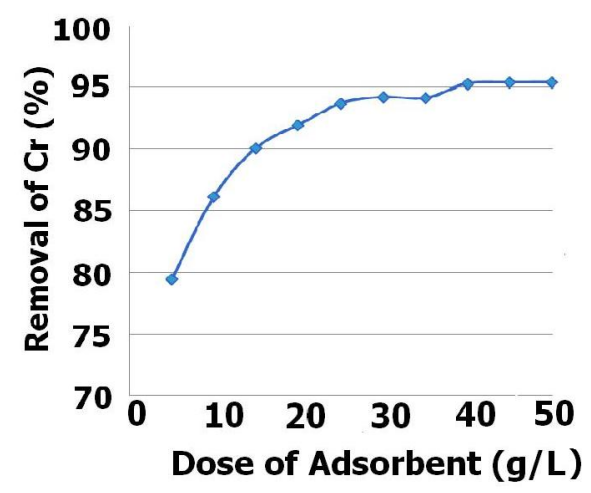

Fig. 6. Effect of dose on the removal efficiency of $\mathrm{Cr}$ on composite

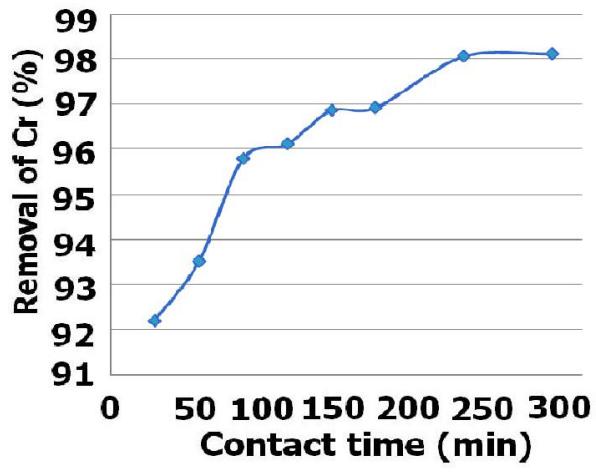

Fig. 7. Effect of contact time on the removal efficiency of $\mathrm{Cr}$ on composite

\section{Effect of contact time}

The interaction of adsorbent and chromium contained solution was performed at $\mathrm{pH} 4.0$ and adsorbent dose was $20 \mathrm{~g} / \mathrm{L}$. The contact time for treatment was varied from $30 \mathrm{~min}$ to $300 \mathrm{~min}$ and centrifuging time was $15 \mathrm{~min}$. Fig.7. represents that removal efficiency increases with an increase in contact time before equilibrium is reached.

It can be seen that $\mathrm{Cr}$ removal efficiency of composite increased from $92 \%$ to $98 \%$ when contact time was increased from 30 to 240 min. Optimum contact time for the adsorbent was found to be $240 \mathrm{~min}$. 


\section{Treatment of tannery effluent by composite at optimized condition}

Two sample of tannery effluents described in Tablel were treated by chitosan-charcoal composite at optimized conditions, $\mathrm{pH}=4.0$, dose $=40 \mathrm{~g} / \mathrm{L} \&$ contact time $=240 \mathrm{~min}$ determined by experiments and the removal efficiency was found $90.5 \%$ and $91.9 \%$ for both of the samples Fig. 8 . The efficiency for tannery effluent was somehow less than that of standard chromium solution (95-98\%). This may be due to the presence of other metals in tannery effluent which competed with $\mathrm{Cr}$ to adsorb on chitosan-charcoal composite.

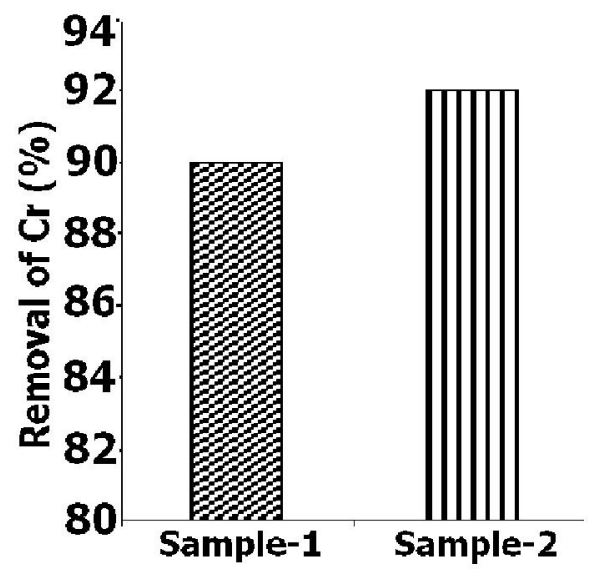

Fig. 8. Removal of Cr from two tannery effluents

\section{Conclusion}

A chitosan-charcoal composite was prepared and characterized by SEM and XRD. The composite was used to remove $\mathrm{Cr}$ from aqueous solution and an optimum condition was found for maximum removal which was used later for the treatment of tannery effluents. The Cr removal efficiency of the composite was more than $90 \%$.

\section{Acknowledgement}

The authors acknowledge the support of Mr. Mainul Ahsan, Director, Institute of Glass and Ceramic Research and Testing and Syed Farid Uddin Farhad Senior Scientific Officer, Industrial Physics Division for providing XRD spectra and SEM. Authors are indebted to former Chief Scientific Officer Md. Asaduzzaman and Bazlul Karim Akanda for their valuable help and suggestion.

\section{R efer ences}

1. A. Kortenkamp, M. Casadevall, S.P. Faux, A. Jenner, R.O.J. Shayer, N. Woodbridge and P. O'Brien, Archives of Biochemistry and Biophysics., 1996, 329,199-208.

2. J. Kotaz and Z. Stasicka, Environnment. Pollut.,2000,107, 263-283.

3. C. Raji and T. S. Anirudhan, Water Res., 1998, 32, 3772. 
4. J. W. Patterson, "Industrial Wastewater Treatment Technology", (2 $2^{\text {nd }}$ edition, ButterworthHeinemann, London, 1985.

5. EPA, Environmental Pollution Control Alternatives EPA/625/5-90/25, EPA/625/4-89/023, Environmental Protection Agency Cincinaati OH USA.(1990)

6. R. A Andersen, Sci. Total Environ., 1989, 86, 75-81.

7. C. S. Gad, Sci. Total Environ., 1989, 86, 149-157.

8. C. G. Maria, Polyhedran., 1996, 15(21), 3667-3918.

9. M. J. Marques, A. Salvador, A. Morales-Rubio and M. de la Guardia, Fresenius J. Anal. Chem., 2000, 367, 601-613.

10. M. M. Islam, S. M. Masum, M. M. Rahman, M. A. Islam, A. A. Shaikh and S.K. Roy, IJ BASIJ ENS., 2011, 11(1), 116-130.

11. P. K. Dutta, J. Dutta and V. S. Tripathi, J. Sc. Ind. Res.,2004, 63, 20-31.

12. T. C. Yang, and R. R. Zall, Industrial and Engeneering Chemistry Produc Research and Developmet., 1984, 23, 168-172.

13. J.R. Deans, and B.G. Dixon, Water Research, 1992, 26(4), 469-472.

14. M. Saifuddin, Nomanbhay and K, Palanisamy, Electronic Journal of Biotechnology, 2005, 8(1), 43-53.

15. L. S. Clesceri, A. E. Greenberg and A. D. Eaton, "Standard methods for the examination of water and wastewater". (20th edition). American Public Health Association, Washington, 1998, 1325.

16. P. Udaybhaskar, L. Iyengar, and R. A. V. S. Prabhakara, J ournal of A pplied Polymer Science., 1990, 39(3), 739-747.

17. T. J Olin, J.M. Rosado, S. E. Bailey and R.M. Bricka Low cost sorbents screening and engineering analysis of zeolite for treatment of metals contaminated water and soil extracts final report. Report SERDP, 1996; 96-387, prepared for USEPA and SERDP.

18. L. R. Radovic, I. F. Silva, J. I. Ume, J. A. Menendez, L. Y. Leon, and A.W. Scaroni., Carbon, 1997, 35(9), 1339-1348.

19. P. C. C. Faria, J. J. M. Orfao and M. F. R. Pereira., Water Research, 2004, 38(8), 2043-2052.

20. M. R. Mostafa, Adsorption Science and Technology., 1997,15(8), 551-557.

21. C. A. Toles, W. E. Marshall and M. M. Johns, Carbon., 1999, 37(8), 1207-1214.

(Received : 7 January, 2012; Accepted : 11 March, 2012) 
J ournal of Bangladesh Chemical Society, Vol. 24(2), 97-105, 2011

*Author for Corresponding ; e-mail : mmipavel@ yahoo.com 